\title{
The Prevention of Finger Sucking and Its Link with Undergraduate Students
}

\author{
Grethel Cisneros Dominguez* and Jorge Carlos Abad Araujo \\ Department of Professional Training, University of Medical Sciences of Santiago de Cuba, Cuba
}

Corresponding author: Grethel Cisneros Dominguez, Department of Professional Training, University of Medical Sciences of Santiago de Cuba

ARTICLE INFO

Received: 幽 October 20, 2020

Published: October 30, 2020

Citation: Grethel Cisneros Dominguez, Jorge Carlos Abad Araujo. The Prevention of Finger Sucking and Its Link with Undergraduate Students. Biomed J Sci \& Tech Res 31(4)-2020. BJSTR. MS.ID.005121.

Keywords: Prevention; Undergraduate; Finger Sucking

\begin{abstract}
Summary
Arduous teaching work must be carried out with the undergraduate student of the Stomatology career from their formative stage and within them are preventive actions to correct inappropriate practices that help prevent dentomaxillofacial anomalies modify habits and improve the quality of life of our infants being considered one of the main tasks in contemporary Dentistry. The success of this instruction does not only lie in the knowledge of the health guidelines that the student can sustain through theoretical knowledge, but that they learn through practice to transmit healthy habits that are nothing more than behaviors that will allow them to children how to care for and maintain their oral health and that to a certain extent guarantees a healthy life, without having to resort to other treatments of prolonged therapeutic regimens for orthodontic purposes.
\end{abstract}

\section{Introduction}

Malocclusions are oral alterations that have a high prevalence worldwide, in which habits occupy one of the risk factors that intervene in their occurrence [1], hence the need to prevent them from early in life, prepare the student of the career, is to appropriate the tools necessary to achieve a better professional performance and reduce the prevalence and the effects they generate. These malocclusions can appear from childhood and are preventable in many cases with correct habits of hygiene, food, behaviors and attitudes that are not born with people but must be cultivated from the first moments of life [2]; What is propitious, comment on how habits and specifically that of finger suction is capable of causing great alterations when it is not treated in time causing severe alterations to the oral complex. It must be of wide domain for the undergraduate student that in the case of the habit of finger sucking can bring alarming consequences to the stomatognathic complex, being affected orofacial structures and the occlusion of the individual, for which arduous, preventive and tenacious work is imposed both students and specialists reaching directly to patients and families.

\section{Developing}

Regarding the habit of sucking in dentistry, there are two forms of suction, one linked to nutritive sucking and the other considered non-nutritive [3]. The digital suction initially constitutes an aid to complement the demands through a nutritious suction, where breastfeeding and feeding with a bottle, jugs, etc., are essential sources of food and through which the baby obtains the necessary nutrients for its sustenance. In relation to a non-nutritive sucking, which differs from the nutritive one, the child is able to use objects such as fingers, pacifiers, cloths or toys that can serve mainly to satisfy psychological needs and these contribute greatly to the development of malocclusions [3]. which means it is important to know it in order to find solutions with a view to preventing them. From a psychological point of view, this practice should be specified because sometimes many of the causes of this ingrained habit are related to psychic aspects [4], therefore early discarding the causes that produce it helps to a great extent to dissipate occlusion alterations which later they affect the facial aesthetics that negatively affects the patient. Non-nutritive sucking habits in all cases can be modifiable3, but preventive work by students and specialists is necessary, as well as early communication with children carrying this habit, parents and relatives who greatly help to improve this habit.

An excessive sucking habit can trigger occlusal effects that, from an orthodontic point of view, have repercussions in physical side effects of excessive digital suction and translate into anterior open 
bite, increased overshoot, lingual inclination of lower incisors and labial inclination of upper incisors, bite posterior cross, protractile tongue, deep palatal vault, speech defects, finger defects, creating an eczema of the finger due to the dryness and humidity that occurs alternately, and even angulations of the fingers due to habit, retrusion mandibular with persistence of a convex profile as well as Diastema in the midline compared to the midline of the face, and other aspects of a facial nature that generate not only oral problems $[5,6]$, in addition to the psychosocial repercussion that this creates. These defects that may appear during the persistence of the habit can be avoided with an arduous, indissoluble and incessant preventive treatment that contributes to a high quality of life from an early age, playing a fundamental role, the teacher's leadership and the student's actions, without underestimate the role of the family as a fundamental link in this process, which would largely dispense with the placement of orthodontic appliances, which on many occasions generate discomfort, abandonment of treatments and large costs.

The knowledge about the prevention that students must have to prevent habits, such as finger sucking and prevent the installation of Dentomaxillofacial Anomalies, greatly favors treating a health problem and improving the route to avoid the development of problems induced by said habit. The teacher has the duty to train and teach students, as well as to guide parents on how the individual grows and develops, how diseases can be prevented at their age and the adoption of a healthier lifestyle, taking advantage of who are in a stage of physical, mental and social formation, with a great capacity for learning and assimilation of positive patterns for life.

\section{ISSN: 2574-1241}

DOI: 10.26717/BJSTR.2020.31.005121

Grethel Cisneros Dominguez. Biomed J Sci \& Tech Res

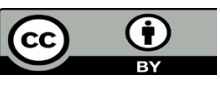

This work is licensed under Creative Commons Attribution 4.0 License

Submission Link: https://biomedres.us/submit-manuscript.php

\section{Conclusion}

This work allows establishing a direct link from theoretical knowledge and stomatological practice with the undergraduate student's training, favoring the same to increase their scientific knowledge and at the same time providing information about one of the problems that affect pediatric patients and its consequences on the oral complex. Instructing the undergraduate student in significant aspects of what they would face in their community, or population as part of the professional performance model, would be a wise idea to try, always seeking to develop disciplinary proposals in the stomatological field, which allows the development of new knowledge and strategies that help improve oral health related specifically to the habit of finger sucking.

\section{References}

1. Korner AF, Reider N (1955) Psychologic Aspects of Disruption of Thumbsucking by Means of Dental Appliance. Angle Orthodontist 25(1): 23-31.

2. Rochat P (2015) The Development of coordination in Infancy. Elsevier Science Publishers B.V.

3. Warren (2005) Nonnutritive sucking and the mixed dentition. Pediatric Dentistry [Internet].

4. Horne RS, Witcombe NB, Yiallourou SR, Richardson HL (2010) Sudden infant deathsyndrome: implications of altered physiological control during sleep. Curr Pediatr Rev [Internet] 6 (1): 30-38.

5. Indushekar GB, Gupta B, Indushekar KR (2012) Childhood thumb sucking habit: theburden of a preventable problem ! Journal of Dentistry, Medicine and MedicalSciences. [Internet] 2 (1): 1-4.

6. (1999) American Academy of Cosmetic Dentistry. Thumbsucking - stop it early.Madison: Pediatric Dentistry [Internet] 1999.

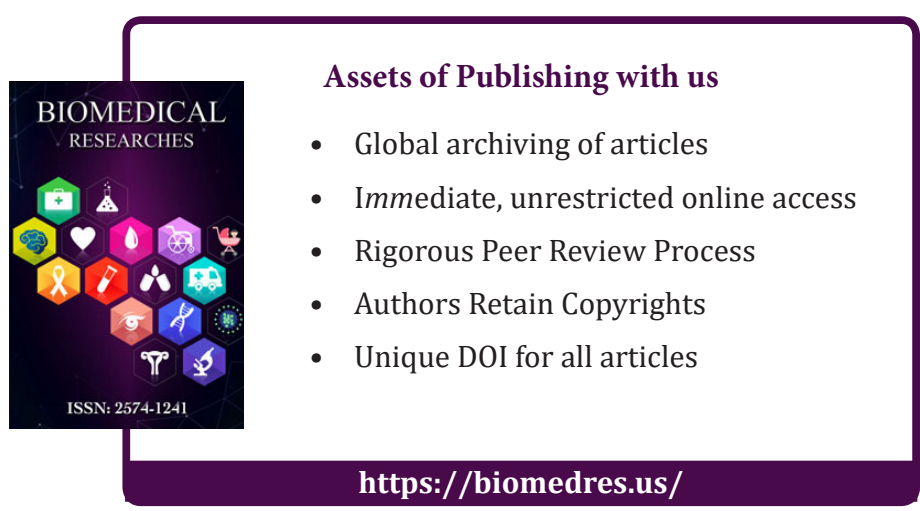

Copyright@ Grethel Cisneros Dominguez | Biomed J Sci \& Tech Res | BJSTR. MS.ID.005121. 